\title{
Acute hyperinsulinemia is associated with increased circulating levels of adrenomedullin in patients with type 2 diabetes mellitus
}

\author{
Akira Katsuki, Yasuhiro Sumida, Esteban C Gabazza, Shuichi Murashima ${ }^{1}$, Hideki Urakawa, Kohei Morioka, \\ Nagako Kitagawa, Takashi Tanaka, Rika Araki-Sasaki, Yasuko Hori, Kaname Nakatani ${ }^{2}$, Yutaka Yano and \\ Yukihiko Adachi \\ Third Department of Internal Medicine, ${ }^{1}$ Department of Radiology and ${ }^{2}$ Department of Laboratory Medicine, Mie University School of Medicine, \\ 2-174 Edobashi, Tsu, Mie 514-8507, Japan
}

(Correspondence should be addressed to A Katsuki; Email: katuki-a@clin.medic.mie-u.ac.jp)

\begin{abstract}
Objective: To investigate the effect of acute hyperinsulinemia on the plasma levels of adrenomedullin (AM) in patients with type 2 diabetes mellitus.

Design: We measured the plasma levels of AM in 18 patients with type 2 diabetes mellitus and in 19 normal subjects before and during a euglycemic hyperinsulinemic clamp study (the goal was for blood sugar levels of $5.24 \mathrm{mmol} / \mathrm{l}$ and insulin levels of $1200 \mathrm{pmol} / \mathrm{l})$. Both plasma AM and serum insulin were measured by immunoradiometric assays.

Results: Before the glucose clamp study there was no significant difference in the plasma levels of AM between patients with type 2 diabetes mellitus and normal subjects. During the glucose clamp study, the serum levels of insulin significantly increased (from $33.0 \pm 3.6$ to $1344.6 \pm 67.8 \mathrm{pmol} / \mathrm{ml}$, $P<0.001$ ), as did the plasma levels of AM (from $12.8 \pm 0.7$ to $14.2 \pm 0.9 \mathrm{fmol} / \mathrm{ml}, P<0.03$ ) only in patients with type 2 diabetes mellitus. There was a significant correlation between the change in circulating levels of insulin and AM $(r=0.755, P<0.01)$.

Conclusions: Acute hyperinsulinemia induced a significant increase in the plasma levels of AM in patients with type 2 diabetes mellitus. Increased insulin may regulate circulating levels of AM in patients with type 2 diabetes mellitus.

European Journal of Endocrinology 147 71-75
\end{abstract}

\section{Introduction}

Adrenomedullin (AM), a potent vasodilator, has been reported to be expressed in several tissues including adrenal medulla, pancreatic islets, vascular smooth muscle and endothelial cells and to be present in human plasma $(1-3)$. AM is a multifunctional peptide that inhibits insulin secretion from pancreatic islets; elevated plasma AM levels may cause $\beta$-cell dysfunction leading to hyperglycemia as observed in some cases of type 2 diabetes mellitus $(4,5)$.

Increased expression of AM from vessels may be stimulated by hyperglycemia, interleukin-1, tumor necrosis factor- $\alpha$ and glucocorticoids (6-8). However, regulation of AM expression by insulin has not been fully clarified as yet. Recently Nagai et al. (9) reported that acute hyperinsulinemia exerts no influence on the plasma levels of AM in normal subjects (9); however, whether acute insulin infusion affects plasma AM levels in patients with type 2 diabetes mellitus remains unknown.
In the present study, we measured plasma levels of AM before and during acute hyperinsulinemia to examine the effect of insulin on the plasma levels of $\mathrm{AM}$ in patients with type 2 diabetes mellitus.

\section{Subjects and methods}

\section{Subjects}

This study comprised 18 patients with type 2 diabetes mellitus. Data obtained from 19 age-matched healthy subjects were used as the control (Table 1). Body mass index (BMI) was calculated as the body weight (in kilograms) divided by the square of the height (in meters). The diagnosis of type 2 diabetes mellitus was established $4.4 \pm 1.1$ years before the beginning of this study, and it was made according to the diagnostic criteria of the American Diabetes Association (ADA) (10).

All patients with type 2 diabetes mellitus were treated with diet $(1440-1720 \mathrm{kcal} /$ day $)$ consisting of 
Table 1 Clinical characteristics of the study subjects. Data are expressed as the means \pm S.E.M.

\begin{tabular}{lcc}
\hline & $\begin{array}{c}\text { Normal subjects } \\
(n=19)\end{array}$ & $\begin{array}{c}\text { Type 2 diabetic patients } \\
(n=18)\end{array}$ \\
\hline Age (years) & $40.4 \pm 1.4$ & $43.1 \pm 2.3$ \\
Sex (M/F) & $16 / 3$ & $13 / 5$ \\
BMl (kg/m $\left.{ }^{2}\right)$ & $24.0 \pm 0.6$ & $24.2 \pm 0.7$ \\
Duration of diabetes (years) & - & $4.4 \pm 1.1$ \\
HbA1C (\%) & - & $9.2 \pm 0.6$ \\
Fasting glucose (mmol/l) & $4.9 \pm 0.1$ & $8.7 \pm 0.7^{*}$ \\
Fasting insulin (pmol/l) & $30.0 \pm 2.4$ & $33.0 \pm 3.6$ \\
Total cholesterol (mmol/l) & $5.2 \pm 0.1$ & $5.2 \pm 0.2$ \\
HDL cholesterol (mmol/l) & $1.6 \pm 0.1$ & $1.4 \pm 0.1$ \\
Triglyceride (mmol/l) & $1.2 \pm 0.1$ & $1.3 \pm 0.1$ \\
GIR $(\mu \mathrm{mol} / \mathrm{kg} \mathrm{per} \mathrm{min)}$ & $54.1 \pm 3.6$ & $43.4 \pm 3.2^{*}$ \\
Visceral fat area (cm $\left.{ }^{2}\right)$ & $111.0 \pm 10.0$ & $112.1 \pm 9.1$ \\
Subcutaneous fat area (cm $\left.{ }^{2}\right)$ & $112.6 \pm 8.9$ & $114.2 \pm 14.6$ \\
Systolic blood pressure $\left(\mathrm{mmHg}^{*}\right)$ & $122.9 \pm 2.5$ & $131.6 \pm 3.5$ \\
Diastolic blood pressure $(\mathrm{mmHg})$ & $77.7 \pm 1.6$ & $79.4 \pm 2.2$ \\
Adrenomedullin (fmol/ml) & $12.4 \pm 0.5$ & $12.8 \pm 0.7$ \\
\hline
\end{tabular}

${ }^{*} P<0.05$

GIR, glucose infusion rate.

20 energy percent (en\%) protein, $25 \mathrm{en} \%$ fat and $55 \mathrm{en} \%$ carbohydrates and exercise therapy (walking 10000 steps daily). Compliance with dietary therapy was checked by a dietitian once a month. None of the patients had evidence of microangiopathy or macroangiopathy. There were six patients with hypertension (blood pressure $\geq 140 / 90 \mathrm{mmHg}$ ) and six with hyperlipidemia (total cholesterol $\geq 220 \mathrm{mg} / \mathrm{dl}(5.7 \mathrm{mmol} / \mathrm{l})$ or triglyceride $\geq 150 \mathrm{mg} / \mathrm{dl}(1.7 \mathrm{mmol} / \mathrm{l}))$ and they were being treated with diet (sodium restriction $304 \mathrm{mmol} /$ day) alone (11). All subjects were nonsmokers. All of the healthy subjects presented a normal pattern according to the criteria of the ADA and none of them had hypertension, hyperlipidemia or a history of smoking.

Informed consent was obtained from all subjects before the beginning of the study.

\section{Study protocol and methods}

Several variables in blood samples, body fat distribution and blood pressure were evaluated in all subjects.

Acute hyperinsulinemia was induced during the euglycemic hyperinsulinemic clamp study using an artificial pancreas (STG-22; Nikkiso, Tokyo, Japan) (12-14). After overnight bed rest, a priming dose of insulin (Humulin R; Shionogi Pharmaceuticals, Osaka, Japan) was administered at $0800 \mathrm{~h}$, during the initial $10 \mathrm{~min}$ in a logarithmically decreasing manner to raise serum insulin to the desired level ( $1200 \mathrm{pmol} / \mathrm{l})$ rapidly; this level was then maintained by continuous infusion of insulin at a rate of $13.44 \mathrm{pmol} / \mathrm{kg}$ per min for $120 \mathrm{~min}$. Blood glucose was monitored continuously and maintained at the target clamp level $(5.24 \mathrm{mmol} / \mathrm{l})$ by infusing $10 \%$ glucose. The mean amount of glucose given during the last $30 \mathrm{~min}$ was considered to be the glucose infusion rate (GIR) and it was used as the index of peripheral insulin sensitivity. Venous blood was collected before and during the clamp study. After centrifugation, the plasma and serum samples were separated into small aliquots and then frozen at $-20^{\circ} \mathrm{C}$ until used.

$\mathrm{AM}$ in plasma samples was measured using a commercially available immunoradiometric assay kit (Shionogi Pharmaceuticals). Briefly, $100 \mu \mathrm{l}$ standard or plasma samples, biotinylated anti-AM, ${ }^{125}$ I-labeled AM antibody and one bead coated with anti-biotin antibody were placed in polystyrene tubes. Thereafter, the mixture was incubated at $4{ }^{\circ} \mathrm{C}$ for a further $20 \mathrm{~h}$. After removal of the incubation mixture, the beads were washed twice with $2 \mathrm{ml}$ distilled water and the radioactivity was measured with a gamma counter. The values of plasma AM levels were then extrapolated from a curve drawn using standard concentrations of AM. This assay showed no significant cross-reactivity with or interference by other factors related to AM (proadrenomedullin, amylin, neuropeptide Y, calcitonin and calcitonin gene-related peptide). The detection limit of this assay was $2 \mathrm{fmol} / \mathrm{ml}$, and the intra- and interassay coefficients of variation were $7.0 \%$ and $6.9 \%$ respectively.

The plasma glucose level was measured by an automated enzymatic method. The hemoglobin $A_{1 c}$ (HbA1c) (normal value 4.3-5.8\%) was measured by high performance liquid chromatography. Serum levels of total cholesterol, triglyceride and high density lipoprotein (HDL) cholesterol were measured by enzymatic methods using an autoanalyzer (TBA60M; Toshiba, Tokyo, Japan). Serum insulin was measured using an immunoradiometric assay kit (Insulin Riabead II kit; Dainabot, Tokyo, Japan). Briefly, insulin standards or serum samples were incubated in the presence of 
${ }^{125}$ I-labeled and unlabeled anti-human insulin mouse monoclonal antibodies at $20^{\circ} \mathrm{C}$ for $2.5 \mathrm{~h}$ while shaking (200 r.p.m.). The tubes containing the mixture were then washed three times with $1 \mathrm{ml}$ washing solution and the radioactivity was then counted. The radioactivity values were extrapolated from a curve drawn using standard concentrations of insulin. The intraand interassay coefficients of variation of the assay were $1.9 \%$ and $2.0 \%$ respectively. No significant crossreactivity or interference were observed between insulin and proinsulin, C-peptide, glucagon, secretin and gastrin-I.

In addition, we measured blood pressure in patients who were supine and had rested for $5 \mathrm{~min}$.

Body fat distribution was evaluated by a previously described method (15). The intra-abdominal visceral fat and subcutaneous fat areas were measured in all subjects by abdominal computed tomography scanning taken at the umbilical level. Any intraperitoneal region having the same density as the subcutaneous fat layer was defined as a visceral fat area.

\section{Statistical analysis}

Data are expressed as the means \pm S.E.M. Comparisons between normal and type 2 diabetic subjects were made using the Mann-Whitney $U$ test. Statistical difference between AM levels before and during clamp study was analysed by the paired $t$-test. The strength of correlation between variables was calculated using
Spearman's rank correlation. Statistical analyses were carried out using the StatView IV software program for the Macintosh (Abacus Concepts, Berkeley, CA, USA). A $P$ value $<0.05$ was considered to be statistically significant.

\section{Results}

No significant differences were observed in the plasma levels of AM between type 2 diabetic patients and normal subjects (Table 1). Plasma levels of AM in hypertensive patients with type 2 diabetes mellitus $(15.0 \pm 0.8 \mathrm{fmol} / \mathrm{ml})$ were significantly increased as compared with normotensive patients (11.8土 $0.7 \mathrm{fmol} / \mathrm{ml}, \quad P<0.03$ ). The BMI (hypertensive patients: $24.5 \pm 1.4$; normotensive patients: $24.1 \pm 0.8$ ), fasting plasma glucose levels (hypertensive patients: $8.0 \pm 0.8 \mathrm{mmol} / \mathrm{l}$; normotensive patients: $8.9 \pm$ $0.9 \mathrm{mmol} / \mathrm{l}$ ), HbA1c (hypertensive patients: $8.9 \pm 0.9 \%$; normotensive patients: $9.4 \pm 0.8 \%$ ) and fasting serum insulin levels (hypertensive patients: $37.8 \pm 6.6 \mathrm{pmol} / \mathrm{l}$; normotensive patients: $31.2 \pm 4.8 \mathrm{pmol} / \mathrm{l}$ ) were not significantly different between hypertensive and normotensive diabetic patients. A significant positive correlation was observed between the plasma levels of AM and the systolic blood pressure only in type 2 diabetic patients ( $r=0.736, P<0.01)$. The plasma levels of AM were not significantly correlated with the plasma levels of glucose $(r=0.161, P=0.547)$, serum levels of insulin
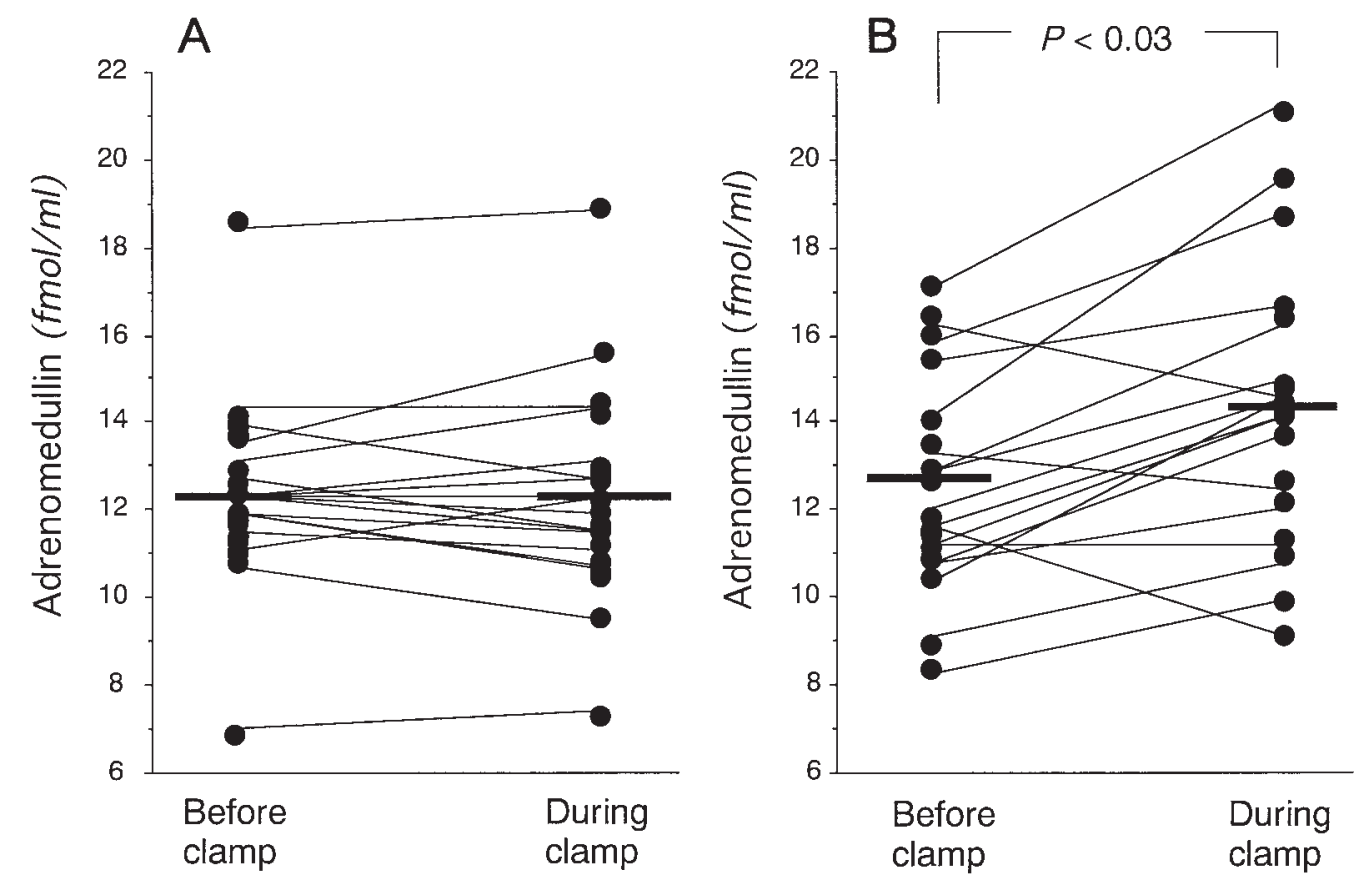

Figure 1 Effect of acute hyperinsulinemia on the plasma levels of AM in (A) normal subjects and (B) patients with type 2 diabetes mellitus. The horizontal lines represent the means. The plasma levels of adrenomedullin increased significantly $(P<0.03)$ during the clamp study in patients with type 2 diabetes mellitus. 
$(r=0.255, P=0.324)$, GIR $(r=0.041, P=0.873)$, visceral fat area $(r=-0.312, P=0.227)$ or subcutaneous fat area $(r=-0.050, P=0.846)$ in patients with type 2 diabetes mellitus.

A significant increase in the plasma levels of AM was observed (from $12.8 \pm 0.7$ to $14.2 \pm 0.9 \mathrm{fmol} / \mathrm{ml}$, $P<0.03$ ) (Fig. 1B) concomitantly with the increase in the blood concentrations of insulin (from 33.0 \pm 3.6 to $1344.6 \pm 67.8 \mathrm{fmol} / \mathrm{ml}, P<0.0001)$. In normal subjects, no significant changes in the plasma AM levels (from $12.4 \pm 0.5$ to $12.3 \pm 0.5 \mathrm{fmol} / \mathrm{ml}$ ) were observed during the acute hyperinsulinemia (from $30.0 \pm 2.4$ to $1295.4 \pm 45.6 \mathrm{pmol} / \mathrm{ml}, \quad P<0.0001)$ (Fig. 1A).

There was a significant correlation between the change in serum levels of insulin and that in plasma levels of AM in patients with type 2 diabetes mellitus $(r=0.755, \quad P<0.01) \quad$ (Fig. 2). Changes in the plasma levels of AM were not significantly correlated with the fasting plasma levels of glucose $(r=0.293$, $P=0.273)$, fasting serum levels of insulin $(r=$ $0.274, P=0.289)$, GIR $(r=-0.031, P=0.905)$, visceral fat area $(r=-0.003, P=0.991)$ or subcutaneous fat area $(r=-0.206, P=0.425)$ in patients with type 2 diabetes mellitus.

\section{Discussion}

The present study showed that the plasma level of AM is elevated during acute hyperinsulinemia in patients with type 2 diabetes mellitus.

Sympathetic activation that occurs during acute hyperinsulinemia may increase AM from the adrenal medulla. Pancreatic islets may also be a source of AM; in this connection elevated levels of plasma AM have been reported in patients with insulinoma (3). Acute hyperinsulinemia may stimulate AM production from pancreatic islets. Although we did not evaluate the endothelial response during acute hyperinsulinemia, the increased blood levels of AM may compensate for the decreased vasodilatory effect of insulin in patients with type 2 diabetes mellitus (16-18). On the other hand, because AM may decrease insulin secretion, the increased levels of plasma AM may be an adaptive mechanism to decrease hyperinsulinemia (4). However, we found no significant correlation between the plasma levels of AM and fasting serum levels of insulin. It is conceivable that physiological fasting levels of insulin observed in our patients do not affect circulating AM. Further study is needed to clarify the source of plasma AM and the mechanism of its elevation during acute hyperinsulinemia.

Additional findings in the present study were the significant correlation between plasma levels of AM and systolic blood pressure in patients with type 2 diabetes mellitus, as well as increased plasma levels of AM in hypertensive patients with type 2 diabetes mellitus. There is not yet a clear explanation for these findings but it is possible that the increased plasma levels of AM play a protective role against arterial hypertension in type 2 diabetic patients.

It has been previously reported that the plasma levels of AM are increased in patients with type 2 diabetes mellitus (19). However, Kinoshita et al. (20) and the present study found no significant elevation when the effect of nephropathy was excluded. Although hyperglycemia has been reported to increase vascular AM

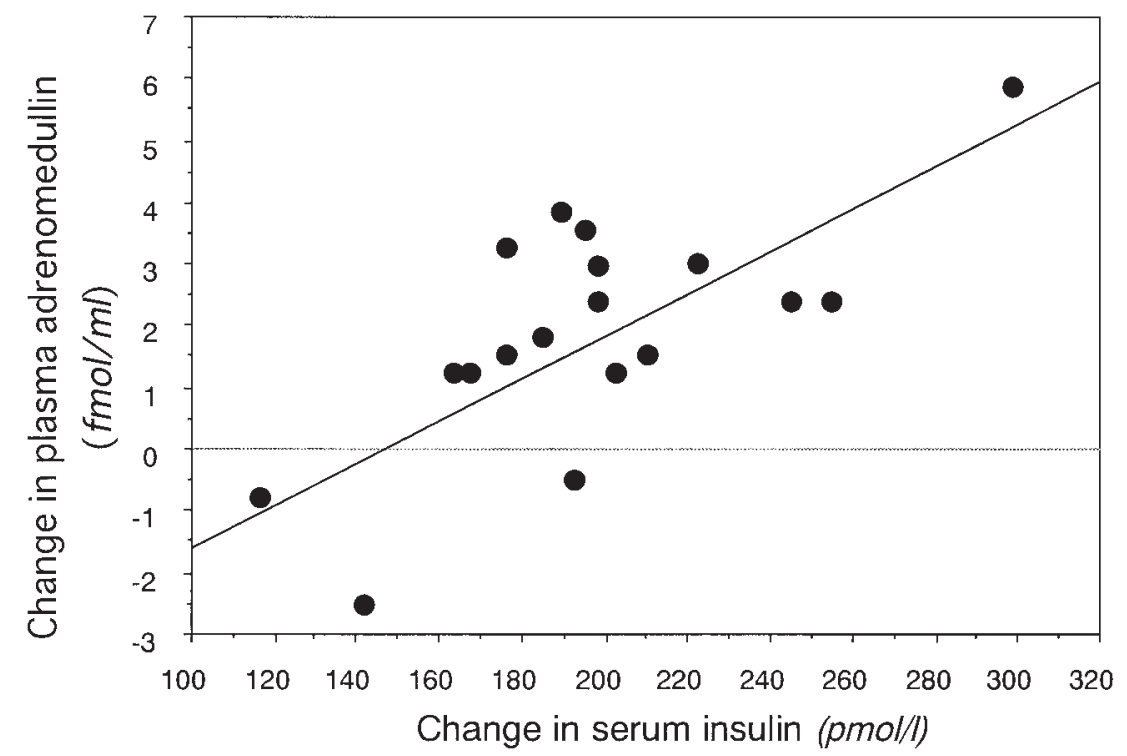

Figure 2 Correlation between changes in serum levels of insulin and in the plasma levels of AM in patients with type 2 diabetes mellitus. A significant positive correlation was observed $(r=0.755, P<0.01)$. 
expression (6) it may act only in the local vasculature and may not influence the circulating levels of AM. Differences in plasma levels of glucose (casual plasma glucose levels: $30.1 \pm 14.8 \mathrm{mmol} / \mathrm{l}$ (19) vs fasting plasma glucose levels: $7.3 \pm 0.3 \mathrm{mmol} / \mathrm{l}(20)$, or fasting plasma glucose levels: $8.7 \pm 0.7 \mathrm{mmol} / \mathrm{l}$ (present study)) may explain these discrepant findings.

In conclusion, acute hyperinsulinemia was associated with elevated circulating levels of AM in patients with type 2 diabetes mellitus. Increased insulin may regulate circulating AM levels in patients with type 2 diabetes mellitus.

\section{References}

1 Kitamura K, Kangawa K, Kawamoto M, Ichiki Y, Nakamura S, Matsuo $\mathrm{H}$ et al. Adrenomedullin: a novel hypotensive peptide isolated from human pheochromocytoma. Biochemical and Biophysical Research Communications 1993192 553-560.

2 Ichiki Y, Kitamura K, Kanagawa K, Kawamoto M, Matsuo H \& Eto T. Distribution and characterization of immunoreactive adrenomedullin in human tissue and plasma. FEBS Letters 199423 $6-10$.

3 Letizia C, Tamburrano G, Alo P, Paoloni A, Caliumi C, Marinoni E et al. Adrenomedullin, a new peptide, in patients with insulinoma. European Journal of Endocrinology 2001144 517-520.

4 Martinez A, Weaver C, Lopez J, Bhathena SJ, Elsasser TH, Miller M-J et al. Regulation of insulin secretion and blood glucose metabolism by adrenomedullin. Endocrinology 1996137 2626-2632.

5 Martinez A, Elsasser TH, Bhathena SJ, Pio R, Buchanan TA, Macri CJ et al. Is adrenomedullin a causal agent in some cases of type 2 diabetes? Peptides 199920 1471-1478.

6 Hayashi M, Shimosawa T \& Fujita T. Hyperglycemia increases vascular adrenomedullin expression. Biochemical and Biophysical Research Communications 1999258 453-456.

7 Sugo S, Minamino N, Shoji H, Kangawa K, Kitamura K, Eto T et al. Interleukin-1, tumor necrosis factor and lipopolysaccharide additively stimulate production of adrenomedullin in vascular smooth muscle cells. Biochemical and Biophysical Research Communications $199520725-32$.

8 Imai T, Hirata Y, Iwashina Kangawa M \& Marumo F. Hormonal regulation of rat adrenomedullin gene in vasculature. Endocrinology $19951361544-1548$.
9 Nagai Y, Yamashita H, Takamura T \& Kobayashi K-I. Does acute hyperinsulinaemia change plasma adrenomedullin concentration in healthy men? Diabetic Medicine 200017 249-250.

10 The Expert Committee on the Diagnosis and Classification of Diabetes Mellitus. Report of the Expert Committee on the Diagnosis and Classification of Diabetes Mellitus. Diabetes Care 1997 $101183-1197$.

11 American Diabetes Association. Evidence-based nutrition principles and recommendations for the treatment and prevention of diabetes and related complications (Position Statement). Diabetes Care 200225 (Suppl 1) S50-S60.

12 DeFronzo RA, Tobin JD \& Andres R. Glucose clamp technique: a method for quantifying insulin secretion and resistance. American Journal of Physiology 1979237 E214-E223.

13 Katsuki A, Sumida Y, Gabazza EC, Murashima S, Furuta M, ArakiSasaki R et al. Homeostasis model assessment is a reliable indicator of insulin resistance during follow-up of patients with type 2 diabetes. Diabetes Care 200124 362-365.

14 Katsuki A, Sumida Y, Gabazza EC, Murashima S, Tanaka T, Furuta $\mathrm{M}$ et al. Plasma levels of agouti-related protein are increased in obese men. Journal of Clinical Endocrinology and Metabolism 200186 1921-1924.

15 Tokunaga K, Matsuzawa Y, Ishikawa K \& Tarui S. A novel technique for the determination of body fat by computed tomography. International Journal of Obesity 19837 437-445.

16 Calles-Escandon J \& Cipolla M. Diabetes and endothelial dysfunction: a clinical perspective. Endocrine Reviews 200122 36-52.

17 Cleland SJ, Petrie JR, Small M, Elliott HL \& Connell JMC. Insulin action is associated with endothelial function in hypertension and type 2 diabetes. Hypertension 200035 507-511.

18 Kinoshita J, Tanaka Y, Niwa M, Yoshii H, Takagi M \& Kawamori R. Impairment of insulin-induced vasodilation is associated with muscle insulin resistance in type 2 diabetes. Diabetes Research and Clinical Practice 200047 185-190.

19 Hayashi M, Shimosawa T, Isaka M, Yamada S, Fujita R \& Fujita T. Plasma adrenomedullin in diabetes. Lancet 19973501449 1450.

20 Kinoshita H, Kato K, Kuroki M, Nakamura S, Kitamura K, Hisanaga $\mathrm{S}$ et al. Plasma adrenomedullin levels in patients with diabetes. Diabetes Care 200023 253-254.

Received 28 November 2001

Accepted 25 March 2002 